\title{
Thinking on the Philosophy, Model, Technology and Development Prospects of School of the Future
}

\author{
Bing Li \\ School of Political Science and Public Administration \\ University of Electronic Science and Technology \\ Chengdu, P.R.China
}

\author{
Ke Niu \\ School of Political Science and Public Administration \\ University of Electronic Science and Technology \\ Chengdu, P.R.China
}

\begin{abstract}
The demand for talents and the mode of education and training have been changed tremendously in the new round of information technology revolution and the era of big data. The School of the Future will become the weather vane of basic education reform worldwide. This thesis will have a in-depth analysis of the connotation and the essence of School of the Future in three dimensions: the philosophy, model and technology level as well as their characteristics and requirements, so as to provide thinking and make recommendations on the future prospects for the development of School of the Future.
\end{abstract}

Keywords-school of the future; philosophy; model; technology

\section{The BACKGRound to Propose the SCHOOL OF THE FUTURE AND ITS MEANING}

Collins - A and Halverson - R, both American educators, put forward the famous "Three Eras of Education" in their coauthored book titled Rethinking Education in the Age of Technology: The Digital Revolution and Schooling in America, which includes apprenticeship era, schooling eras, and lifelong learning era of education [1]. Significant changes are witnessed of these three eras in aspects of responsibility, expectations, content, pedagogy, assessment, location, culture and relationships. In the apprenticeship era, education was mainly about learning practical skills in a relationship between master and apprentice. With the development of Industrial Revolution, productivity was substantially increased, and large-scale and standardized schooling had become the main features of this era. Finally, the high speed of knowledge update brought by technological revolution opened the door of lifelong learning to human beings.

In the background of revolution of the new era, the reform of basic education should also takes on new look and shows new direction, including re-defining the concept, pedagogy and operating means of the future basic education. We regard the future basic education system, which is based on ICT

(Information、Communication、 Technology), generally as

"School of the Future". This concept was first originated from a real "School of the Future" founded by the Philadelphia School District and Microsoft on September 7, 2006. This school made great innovation in the way of learning, learning environment, and management method, which exactly meets the requirements of lifelong learning era and the education reform under the new technological revolution.

School of the Future is no longer just a simple school or place; it is the combination of an open environment, growing platform and rich resources to help students face the ever changing and innovative future.

- From the aspect of philosophy: School of the Future helps students have comprehensive as well as personal abilities to learn with open, integrated, and selfconscious attitude.

- From the aspect of model: School of the Future will build an autonomous and constructive education model and humanized management model.

- From the aspect of technology: School of the Future, which is based on high and new technology, will gradually reduce the boundaries of learning time and space by embedding teaching process and hardware and software of information technology, giving full play of information technology to serve education, and ultimately to realize lifelong learning.

\section{NeW TRAINING Philosophy OF SchoOl OF THE FUTURE}

The word "philosophy", first proposed by Plato, is very important in the philosophical category. Essentially, it refers to something that makes something be itself [3]. A school's educational philosophy is the pursuit of ideal education and the faith in basic relationships during the process of running school, such as teaching and learning, development and reform, and ideal and reality[4].

If the education philosophy in apprenticeship era is "closed, passive, and pragmatic", and that of schooling era is "semiclosed, one-direction teaching, standardized knowledge", then in the lifelong learning era, learners will look for and try to obtain resources from every corner around the world. School of the Future will emphasize more on training students with comprehensive as well as personal abilities to learn and grow with open, integrated, self-conscious and active attitude. 


\section{A. Open and Integrated}

Open means that each student in School of the Future should have open mind and idea toward the vast world outside the books, and they can maintain a strong sense of curiosity to all new things and knowledge of the outside world and willing to accept new ideas and new technologies. In Japan's primary and secondary schools, students have access to massive software and e-learning materials and resources through devices on their hands, and those resources are rich in content and fast in updating speed [5].

Integration, on the premise of open mind, means first the collision and fusion in knowledge and second the cross-age exchanges and cooperation. From the perspective of knowledge, students can, under the guidance of teachers, not only access to the open world and knowledge, but also be able to integrate after accumulating knowledge. From the exchange point of view, School of the Future promotes mixed-age communication, which will no longer be limited by background, age, identity or authority. Under the necessary guidance of teachers, all students will be able to open their hearts and have equal exchanges with every people they come into contact. A variety of mind will be gathered together to exchange thoughts and build knowledge.

\section{B. Self-conscious and Active Awareness}

Zimmerman, professor of the City University of New York said: self-regulated learning refers to the "self-regulated students select and use self-regulated learning strategies, on the basis of learning efficiency and learning skills feedback, to achieve desired learning outcomes." [6] School of the Future aims to train students to realize and be capable of having selfregulated and active learning. While the boundaries of learning time and space slowly disappeared, students become masters of learning. In order to promote students' awareness of selfregulated learning, Canberra Primary School of Singapore designs Imprints in its project "Canberra Live" to promote students' awareness to learn. It is a package of school life, which includes a student's relevant information and learning process data. Students can use this tool to have self-regulated learning in accordance with their own learning processes [7].

\section{Comprehensive While Individual Development}

In addition to intelligence education, emphasis should also be put on moral education, physical education, aesthetic education and education of students' personality and value in School of the Future. Besides, on the basis of comprehensive development, it should also concern about the personality development of every individual student and respect each student's personal choice. Primary and Secondary Education (1-9 grades) in Finland implement small class teaching, which allows teachers to play and learn with each child and develop children's personality [8]. Teachers should not only provide students with comprehensive education, but also be good at discovering students' each shining point in their comprehensive abilities, and give further guidance and explore their potential.

\section{SHIFT IN THE MODEL OF SCHOOL OF THE FutURE}

If the ideal and thinking are the invisible soul and the future direction of School of the Future, then the model is the practice carrier and the starting point for reform. To match up with the educational philosophy of School of the Future, that is open, autonomous and comprehensive development, the future education model should be student-oriented and constructive, and the management model should be dynamic and peopleoriented.

\section{A. Student-oriented Learning Model}

Essential changes have been seen among the main parties of future education model. The authority of teachers will gradually be reduced, parents will functioned more in giving guidance, and the role of schools will transfer from centralized management to governance and service. Most importantly, students will become the center in the future education mode. UNESCO made a brilliant exposition on the role of teachers in the future: the responsibility of teachers will be less and less focused on imparting knowledge but incenting to think. A teacher will more and more likely to be a consultant, a participant in exchange of views, and a person who helps to find out contradictions instead of becoming a person who arises as the truth[9]. Taipei Nangang Primary school is the forerunner of building the School of the Future. Students can undertake exploring and autonomous learning on campus through the exploring modules on the "Taipei Nangang Primary APP”. [10]

\section{B. To Establish Interactive and Cooperative Learning under Constructivism}

Constructivism was first promoted by Kant. In his view, a subject cannot be connected with the external world directly, but can only develop knowledge through organizing experience by using the internal constructivism. Jean Piaget, a Swiss psychologist, developed children's cognitive development theory and held that learning is a kind of "selfconstruction". The development process of individual thinking is, on the basis of children gradually becoming mature, the constantly coordinating and constructing process of obtaining individual and social experience during the interaction between subject and object ${ }^{[11]}$.

The Constructivism learning view emphasizes on one hand that learning is a process for students to, based on original knowledge, actively process new information and construct knowledge representation in certain social and cultural environment [12]. On the other hand, this view holds that teachers should guide students to grow new knowledge and experience from the earth of original knowledge and experience. Zhang Yubin proposed that the ideal class is a class of effective interaction: to reconstruct teacher-student relationship, realize teacher-student interaction, and organize cooperative learning among students [13]. In the new teacherstudent relationship of the future, teachers respect students, help students, affect students and trust students. In good mutual influence and exchanges between teachers and students, students will be trained to have the awareness of cooperative learning. The teaching process is both a cognitive process and a process of interaction and aesthetic appreciation. 


\section{Personalized Organization Service Model}

In the development of School of the Future, government should give full trust and appropriate autonomy to schools. Different schools can organize featured activities according to their specific cases. A typical representative of this aspect is Finland. Government and educators trust each other. Government provides funds for schools without doubts, and schools can design and customize reform policies according to their actual situation. This culture of trust has improved the overall quality of education in Finland to the best[14]. According to China's specific national conditions, education still needs unity government regulation. In reform, government should play a major role in macro-control, and properly transfer power to lower level, leaving autonomy and enthusiasm to local and schools.

Internally, school management will tend to be more people-oriented. On the premises of ensuring the progress of teaching and syllabus, teachers can organize the specific form, teaching place and evaluation method of class teaching on their own. Besides, School of the Future will deeply combine administration and technology, and break down the internal and external blocking and barriers among different departments within a school, so as to significantly enhance administrative efficiency, shorten the distance between teaching and administration and receive the effect of wise administration.

\section{TEChNOLOGY OF SCHOOL OF THE FutURE}

There is nothing but the in depth integration between a variety of advanced technology and equipment and education that can most directly reflect the concept of "future". Modern information technology is used to improve the efficiency of classroom teaching, students' motivation to participate and their ability to solve problems. For instance, both projects of Japan's "Promotion of School of the Future" and Singapore's "Intelligent Nation 2015" have emphasized specifically in their "School of the Future" planning that information technology hardware and software and basic education should be deeply connected.

In the process of building School of the Future for almost all governments and schools, the integration of technology and teaching is deemed as the priority in reform. However, have we ever seriously considered what indeed is the relationship between technology and education? There are inevitable local governments and schools who promote information technology for the purpose of information technology itself, taking teachers and students' "degree of informatization" as a criterion to measure the construction of School of the Future. By doing so, technology and education are reversed like putting the cart before the horse. In a real School of the Future, technology is only a means for learners to access resources. To realize personal growth and to train mind and ability, it will ultimately rely on education itself served by technology.

\section{ThOUGHTS ON THE PROSPECTS OF SCHOOL OF THE Future-PhILOSOPHY FIRST, SERVED BY TECHNOLOGY}

First, to have correct philosophy then start to develop School of the Future. Reform should be performed to the deep foundation of education, such as teaching philosophy, personnel training mode, knowledge construction logic, and internal and external management system. The basic education in the future should be like this: students throw off the shackles of school, classroom, teachers and textbooks to autonomously construct their own worldview and knowledge systems and have self-learning, self-development, and self-promotion by means of receiving guidance from teachers and having mixedage exchanges with the aid of a series of technical means.

Secondly, the builders should have cleared the understanding that technology serves education. The ultimate goal of educational informatization is to promote the quality of future-faced education for more people to enjoy better education through the construction of information infrastructure. Technology leaders need to work with educators, not to perform as missionaries with magical gift, but to act as collaborators with educators to create new learning opportunities [15]. Professor Lu Zhicheng, CEO of Tsinghua Tongfang, clearly pointed out that "the core of education information industry is for the information technology to provide a kind of means and service for education to enable people engaged in education with better means to do education...to have profound understanding of education, and able to integrate educational thought, content resources, supporting equipment, and operations services to the unified framework of 'unlimited learning'." [16]

China is now in its infant stage to build School of the Future. It should re-examine its schools in all dimensions under the background of new reform, making clear the future development direction, the respected philosophy, and the paths to be followed. The education reform pace of Finland is of important reference value for China. The basic education reform in Finland, starting from the shared educational philosophy and vision of its people, is good at learning experience and lessons from the past and makes innovation in succession [17]. Such reform does not pursue drastic "moving tendons and bones" macroscopically, but steady "breaking one by one" microcosmically. Although it may be less revolutionary and explosive, only such gradual and accumulative reform can lay a solid foundation for building the future high-rise.

\section{REFERENCES}

[1] [US] Collins • A, [US] Halverson • R. Rethinking Education in the Age of Technology: The Digital Revolution and Schooling in America [M] Chen Jiagang, Cheng Jiaming translate. Shanghai: East China Normal University Press, 2015, (3): P 91.

[2] Feng Daming. Innovation and Indication of the 21 Century Pioneer School - Study and Evaluation on "School of the Future" of Philadelphia of US [J] Global Education, 2007, (6): P67-68.

[3] Zhao Tingyang. The Tianxia System [M]. Nanjing: Jiangsu Education Press, 2005 P40.

[4] Ye Wenzi. On Headmaster's educational philosophy of Middle and Primary Schools [J] Educational Research, 2007, (4):. P85.

[5] Li Zhe, Zhang Hai. Hope Raised in "Schools of the Future" (1): Icebreaker Sail - Summary of Ministry of Internal Affairs of Japan "Promoting Schools of the Future" [J] Chinese Information Technology Education, 2013, (1): P118. 
[6] [US] Barry $-\mathrm{J} \cdot$ Zimmerman etc. Yao Meilin translated. [M] Selfregulated Learning. Beijing: China Light Industry Press, 2001: P17.

[7] Wang Dongmei. Practice and Exploration of Singapore's "School of the Future" and Its Implications for China. [J] Foreign Education, 2012, (4): P40.

[8] Wu Xuechao, Zhang Tao. Analysis on the Development Strategy of Primary and Secondary Education the Social Transformation of Finland. [J] foreign primary and secondary education, 2007, (7):. P17.

[9] UNESCO International Commission on Education Development eds., Institute of Education, East China Normal University Comparative translated [M] Learning to Live - Today and Tomorrow of the world of education. Beijing: Education Science Press, 1996.

[10] Zhang Yi Hua. The Philosophy of wisdom education and wisdom school [J]. Chinese Information Technology Education, 2013, (6)... P16

[11] Tian Yanming, Wang Shujie. Psycho-cognitive Theories and Foreign Language Teaching [M]. Tsinghua University Press, 2010:. P20-28.

[12] Yang Weidong, Jia Nan. Constructivism Learning Theory [J]. Theory Guide Training, 2011, (5):. P79.

[13] Zhang Yubin. Construction and Implementation of the Ideal Classroom - the Ideal Class in the Eye of A Instructors and Researchers [M]. Chongqing: Southwest China Normal University, 2011, (9): P143-193..

[14] Wang Yuefang. Logic and Philosophy of Finland Basic Education Reform [J]. Primary and Secondary Schooling Abroad, 2009, (6):. P10.

[15] [US] Collins • A, [US] Halverson • R. Rethinking Education in the Age of Technology: The Digital Revolution and Schooling in America [M] Chen Jiagang, Cheng Jiaming translate. Shanghai: East China Normal University Press, 2015, (3): P 141

[16] Lu Yao. IT should Serve Education - Dialogue between Executive Editor of this Journal and Professor Lu Zhicheng, Vice Chairman and CEO of Tsinghua Tongfang Co., Ltd. [J]. Distance Education in China. 2004, (6): P23,25..

[17] Wang Yuefang. Logic and Philosophy of Finland Basic Education Reform 